\title{
Asbestos free friction composition for brake linings
}

\author{
ARNAB GANGULY and RAJI GEORGE* \\ M.S. Ramaiah Institute of Technology, MSRIT POST, Bangalore 560 054, India
}

MS received 20 July 2007; revised 1 November 2007

\begin{abstract}
An asbestos free friction material composite for brake linings is synthesized containing fibrous reinforcing constituents, friction imparting and controlling additives, elastomeric additives, fire retarding components and a thermosetting resin. The composite shows exemplary friction characteristics and has great resistance to wear and shows good temperature stability.
\end{abstract}

Keywords. Composite; wear resistance; friction; brake lining.

\section{Introduction}

High friction materials have applications in automotive, aerospace and industrial brake systems. High friction compositions are a three-element composition consisting of a matrix of polymeric blends, reinforcing material, friction and anti-wear material. Among the most well known polymeric systems known, the phenolic resins or modified phenolic resins are the well known thermosets with good thermal stability. Serious health problems are caused by the use of asbestos (commonly used as reinforcement material in friction linings). Asbestos fibres are known to cause lung cancer (Spurr 1972; Jacko et al 1984; Berry 1994; Sophie and Mason 2002; Erdinc et al 2003). Thus, there has been a long felt need to find alternative reinforcing materials for the production of brake linings (Gopal et al 1994, 1996; Dharani et al 1995). Alternate reinforcing materials are being constantly studied. Some known reinforcing materials in use today are generally fibres of Kevlar, glass, carbon, metal and so on. Friction imparting materials are typically carbides, oxides, and nitrides in fine particulate form. Graphite and molybdenum oxide are generally added to increase resistance to wear.

Phenolic resins are among the most commonly used binders in friction materials. They are usually readily mixed with other constituents of friction material composites and therefore, may be used in relatively high content. They offer resistance to temperatures to the order of $250^{\circ} \mathrm{C}$, and they char to high carbon content. Virtually every manufacturer of automotive friction materials uses phenolics as the binder. However, phenolic resins are not without their limitations. Phenolics are also inherently brittle. For this reason, friction material composites are

*Author for correspondence (rgeorgemsrit@rediffmail.com) modified with tougheners such as epoxy resin. Rubber particles are added to increase flexibility and increase braking power. Cashew dust at levels of up to 20 volume percent of the resin content have been added to minimize cracking of the composite. Cashew nut resin is known to increase friction properties of the base thermoset resin which otherwise has a hard smooth finish and also makes it abrasion resistant. Cashew nut shell liquid (CNSL) is a naturally occurring chemical monomer consisting of four alkyl substituted phenols. Cashew nut shell liquid (CNSL), whose main component is cardanol, is a phenol derivative having a meta substituent of a C 15 unsaturated hydrocarbon chain with one to three double bonds. Its phenolic nature makes it suitable for polymerization into resins by formaldehyde. Both additives increase the high temperature limit and the high char yield of a phenolic binder composite and provide an improved resin with increased toughness as measured by compressive strain to failure. This also minimizes the need for toughening additives as required by phenolics and raises the decomposition/char yield (as compared to phenolic resin) of a resin-bonded composite. We have used phenolic resin in combination with epoxy resin, hardeners, rubbers, silicones, cashew nut resins, reinforcing and friction imparting and modifying fillers to form a vastly improved brake composition. While a guide to the percentages of some of the constituting components has been obtained from the references indicated, the appropriate amount of shellac, hardener and other constituents were selected based on the trial and error iterations. The composition was tested for wear, friction and temperature stability.

\section{Experimental}

Asbestos free friction liners were synthesized comprising of the following methodology: A mould was made to generate disc shaped friction linings. $3 \mathrm{~g}$ of phenol for- 
maldehyde was blended with $4 \mathrm{~g}$ of epoxy resin. To the uniformly blended mixture was added $1 \mathrm{~g}$ of CNSL along with $0.8 \mathrm{~g}$ of graphite and the resultant composition mixed well. $0.8 \mathrm{~g}$ of $\mathrm{SiC}$ and $2.2 \mathrm{~g}$ of iron fibre were blended into the mixture. Slowly, $0.5 \mathrm{~g}$ of shellac, $1.5 \mathrm{~g}$ of silica flour and $0.4 \mathrm{~g}$ of silicone resin were added. On obtaining a uniform blend, $1 \mathrm{~g}$ of rubber solution and $0.6 \mathrm{~g}$ of trisphenol hardener were added. The above ratio of phenolic resin and epoxy resin gave a pot life of 4-10 $\mathrm{min}$. The mixture was blended and transferred to a mould for compaction. After allowing the mixture to harden partially, it was compacted in a press at a pressure of about 200 psi to give the shape of the mould.

The compacted sample was then subjected to a preliminary curing process at $60^{\circ} \mathrm{C}$ for $2 \mathrm{~h}$ after which it was post cured at $180^{\circ} \mathrm{C}$ for $3 \mathrm{~h}$.

The prepared sample was then characterized using a scanning electron microscope. For carrying out the electron microscopy, the samples were gold coated to improve quality of the images. Scanning electron microscopy was done on the samples before and after they were subjected to friction testing using a JEOL JSM 5600LV.

The wear tests were done using a pin on disc wear test setup. The setup was connected to a computer to compute the results. Wear testing was done using samples of $10 \mathrm{~mm}$ diameter. Each sample was tested by sliding it against a steel disc and the friction and wear characteristics of the sample was then obtained from the test.

Samples were also subjected to a thermogravimetric analysis to determine the temperature resistance of the composite prepared. About $11.5 \mathrm{mg}$ of the sample was used in thermogravimetric analysis studies.

\section{Results and discussion}

The brake lining material is made up of (a) fibrous materials, (b) abrasive particles, (c) anti-wear materials, (d) fillers and (e) binders, curing agents and heat and wear resistance additives. The resin binder is a critical component. The limits of heat resistance and strength of the frictional material are governed largely by the heat resistance and strength of the resin binder. The temperature attained in high performance braking systems is hot enough to decompose phenolics and similar organics by high temperature oxidation. The phenolic resin first chars, which means it is converted to carbon accompanied by loss of mass, and then ablates into carbon dioxide. Phenolic resins are highly brittle by nature, thus to reduce the brittle nature of the composite, specific ratios of epoxy resin and rubber particles are used. This improves the toughness of the resin-bonded mixture. The composite thus consists of phenolic resin and epoxy resin that function as the base matrix. The matrix is strengthened by reinforcing materials of Fe fibres and friction materials comprising of SiC. Graphite and silica flour are added to act as anti-wear additives and the addition of silicone resins acts as a fire retardant. The cashew nut resin is added to improve the temperature resistance of the composite. Shellac is a natural, organic resin that comes from an insect, Laccifera lacca, that is about the size of an apple seed, used to improve the hardness of the composition. The rubber solution helps reducing the brittle nature of the phenolic base. A curing agent in the form of tris phenol (DMP 30, 2,4,6-tri dimethylaminomethyl phenol) is used to improve the curing time.

The percentage of each component has been selected by trying various permutations and combinations in the percentages for the phenolic and epoxy levels. The same has been done to select the percentages of other filler materials, hardener and the like. For example, a higher percentage of phenolic content created a composite which was extremely brittle. Higher percentages of shellac resulted in a composite which was very hard but with reduced friction characteristics. Similarly, higher percentages of DMP-30 resulted in composites which hardened extremely rapidly and lost its workability and hence, made it increasingly brittle. Increasing the percentage of graphite content increased the wear resistance but at the cost of friction coefficient. The filler contents were chosen at percentages which were optimum for blending and at the same time provided the desired characteristics. Thus, the appropriate composition as indicated have been obtained after a number of iterations and trials and errors associated with them, thus optimizing the process requirements.

The friction material synthesized was subjected to a wear test by making use of a pin on disc wear tester. The tester was coupled to a computer to generate the results for the plot as shown in figure 1 .

The sample used for the test was of $10 \mathrm{~mm}$ diameter and is slid against a rotating steel disc. Initially a load of $0.5 \mathrm{~kg}$ is applied on the sample against a speed of $300 \mathrm{rpm}$ of the rotating disc. An initial period of $200 \mathrm{~s}$ is allowed for attaining stability. Beyond this, it is clear from the plot that there is no wear till the next loading condition. The next loading is applied at $600 \mathrm{~s}$, the increasing trend observed during the loading period in the wear plot is attributed to loading errors. In the region between $600 \mathrm{~s}$

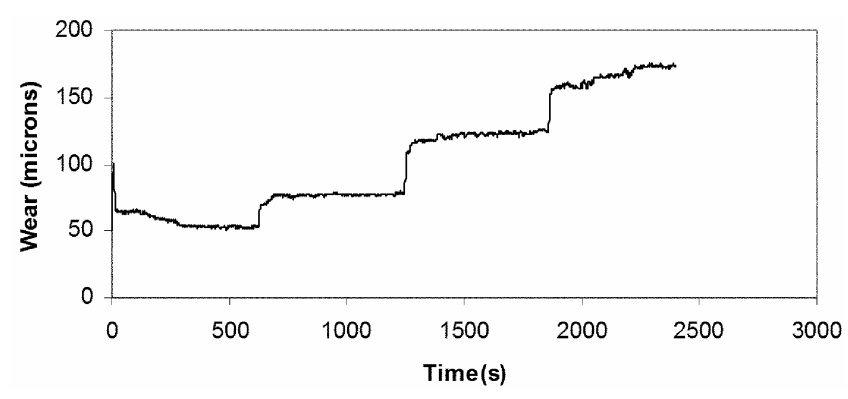

Figure 1. The plot of wear vs time. 
and $1200 \mathrm{~s}$, a load of $1 \mathrm{~kg}$ is applied and the plot again indicates minimal wear during this period with respect to time. A similar trend is observed for the following loading periods. This clearly shows that the composite has exemplary resistance to wear under different loading conditions.

The same setup was used to determine the coefficient of friction of the composite friction lining. The prepared sample was found to exhibit excellent coefficient of friction as illustrated by the plot of coefficient of friction vs load in figure 2 .

The coefficient of friction was found to vary between 0.35 and 0.45 for varying load conditions. The coefficient of friction is governed by the relation

$$
\mu=F / N
$$

where $\mu$ represents the coefficient of friction of the sample, $F$ the frictional force and $N$ represents the normal load.

The prepared sample was also subjected to a test for determining the stopping power of the sample on a similar setup (table 1). The sample was mounted on an arm and the disc was rotated at a fixed arm. The power supply was then cut-off and the angle of rotation of the disc before it came to a halt was noted for varying loads and speeds. It is evident from the table that the high friction characteristics of the sample prepared reduced the rotation of the disc to small angles after cutting off the power which is a necessity for high performance brake linings.

A test was carried out to determine the loss of mass in the sample as a measure of wear over time. The steel disc

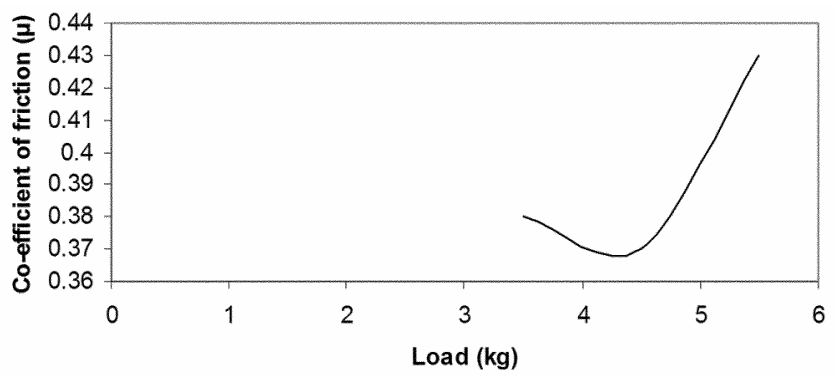

Figure 2. The variation of coefficient of friction exhibited by the sample under varying load conditions.

Table 1. Performance of the sample for the stopping power test under varying loads and speeds.

Angle of rotation

Sl. No. Load (kg) Speed (rpm) before stopping (degrees)

\begin{tabular}{rrrr}
\hline 1 & 1.5 & 50 & 80 \\
2 & 1.5 & 60 & 85 \\
3 & 4.5 & 100 & 130 \\
4 & 4.5 & 120 & 140 \\
\hline
\end{tabular}

was rotated at $500 \mathrm{rpm}$ for $1800 \mathrm{~s}$. The sample was found to have lost $0.002 \mathrm{~g}$ in wear which is almost negligible. This could also be attributed to human errors during mounting and un-mounting.

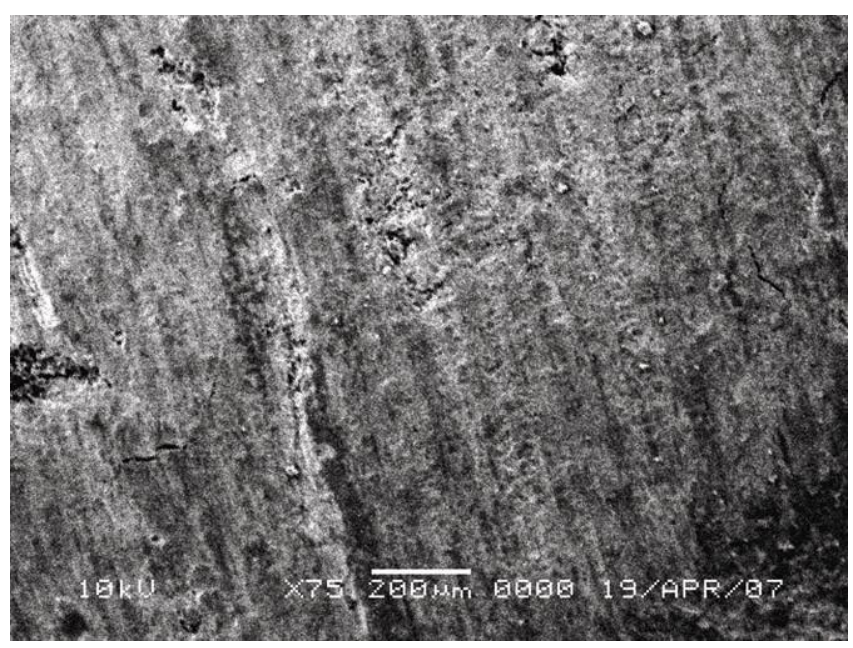

Figure 3. SEM micrograph of sample before wear test.

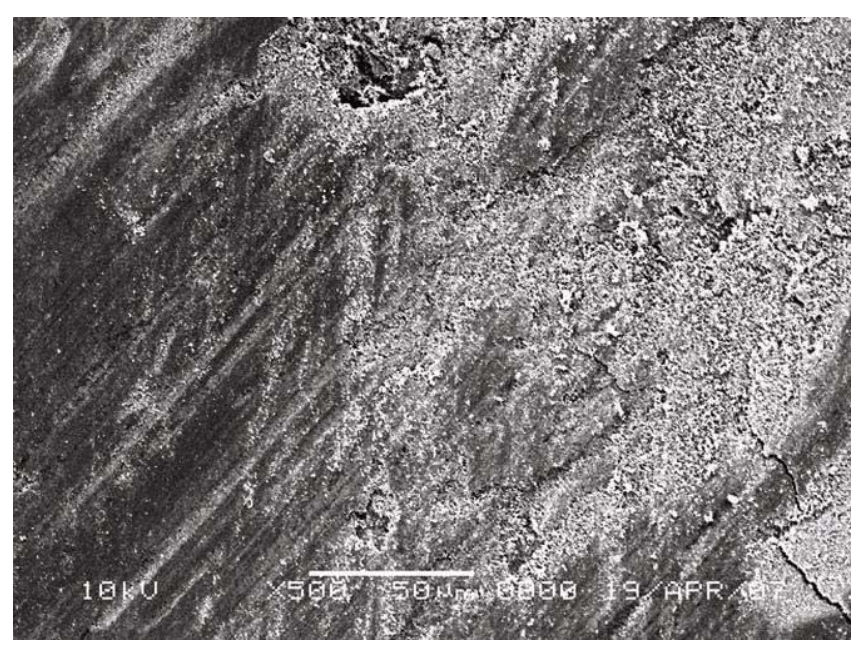

Figure 4. SEM micrograph of the sample after wear test lasting $1800 \mathrm{~s}$.

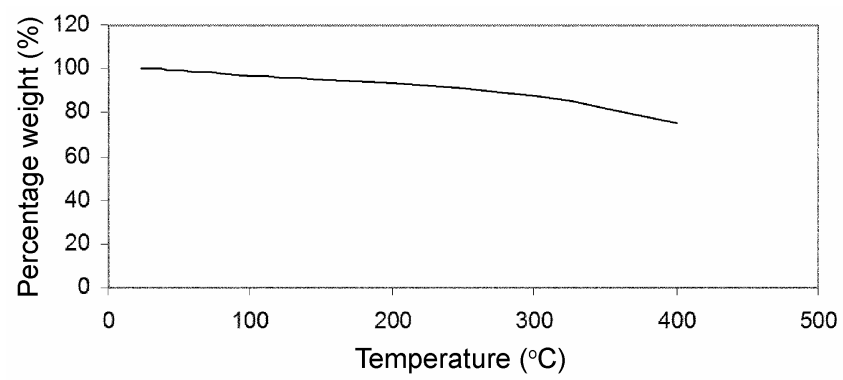

Figure 5. Plot of the thermogravimetric analysis carried out to determine the temperature resistance of the sample. 
Table 2. This table represents the properties for comparison and the corresponding values of the property for a standard non-asbestos brake lining composite.

\begin{tabular}{lc}
\hline Property & Standard for comparison \\
\hline Coefficient of friction & $0 \cdot 3-0 \cdot 4$ \\
Wear rate $\left(\times 10^{-13} \mathrm{~m}^{3} / \mathrm{m}\right)$ & $2 \cdot 4-7 \cdot 4(0 \cdot 5 \mathrm{MPa})$ \\
Maximum temperature $\left({ }^{\circ} \mathrm{C}\right)$ & 175 \\
\hline
\end{tabular}

A scanning electron microscopy (SEM) of the sample was taken before and after the wear test (figure 3).

It is clear from figure 4 that there is a certain amount of void generation after the wear test when compared to figure 3 (before the wear test). However, this void generation is localized and is minimum due to the excellent wear resistance exhibited by the composite.

Figure 5 represents a plot of percentage weight vs temperature. The sample prepared was found to exhibit very high temperature resistance, necessary for vehicle brake linings. The plot clearly indicated that there is a small drop in the plot till $300^{\circ} \mathrm{C}$. Beyond $350^{\circ} \mathrm{C}$, the composite showed a sharper deflection, thus exhibiting a high temperature resistance in the range of $0-350^{\circ} \mathrm{C}$.

It is found that the properties exhibited by the composite are in good agreement with those exhibited by asbestos brake linings and can hence be used to substitute them due to their inherently hazardous characteristics described earlier. It is also evident from table 2 that the characteristics exhibited by the composite synthesized has superior characteristics when compared to the standard values of non-asbestos brake linings as well (Chand et al 2004).

\section{Conclusions}

An asbestos free friction material composite for brake linings is synthesized which contains fibrous reinforcing constituents, friction imparting and controlling additives, elastomeric additives, fire retarding components and a thermosetting resin. The composite synthesized was characterized using SEM technique. The samples were subjected to a number of tests including a wear test, 'thermogravimetric analysis'. It was also found to exhibit exemplary friction and anti-wear characteristics along with providing high temperature stability. The constituents used in the composite are extremely economical and are hence appropriate for industrial applications. The resins used in the composite are priced in the range of $\$ 2.5$ to $\$ 3$ per $\mathrm{kg}$ while the fillers in the range of $\$ 0.25$ to $\$ 1$ per $\mathrm{kg}$. The composite becomes even more economical when manufactured in bulk for industrial applications.

\section{Acknowledgements}

The authors would like to thank Prof. Sanjay Biswas and Dr Somnath Ganguly for their continuous help and guidance during the study. The authors are grateful to Prof. Guru Row for allowing them to use the facilities at the Indian Institute of Science, Bangalore and Mr Tripan Bannerjee for his continued help and guidance. In addition, the authors gratefully acknowledge the support provided by the MS Ramaiah Institute of Technology, Bangalore.

\section{References}

Berry G 1994 Ann. Occup. Hyg. 38539

Chand N, Hashmi S A R, Lomash S and Naik A 2004 IE(I)Journal-MC 8513

Dharani L R, Gopal P and Blum F D 1995 Wear 181913

Erdinc M, Erdinc E, Cok G and Polatli M 2003 Environ. Res. 91151

Gopal P, Dharani L R and Blum F D 1994 Wear 174119

Gopal P, Dharani L R and Blum F D 1996 Wear 193199

Jacko M G, Tsang P H S and Rhee S K 1984 Wear 100503

Sophie K T and Mason E 2002 in Asbestos: Minerals and fibres (New York: American Chemical Society) p. 175

Spurr R T 1972 Wear 22367 